\title{
INVENTÁRIO MACROECONÔMICO DO GOVERNO LULA ${ }^{1}$
}

\author{
José Maria Alves da Silva ${ }^{2}$ \\ Daniel Arruda Coronel ${ }^{3}$
}

\begin{abstract}
Resumo: Com base em análise de indicadores econômicos do Brasil no período 19952010, esse trabalho tem o objetivo de estabelecer uma avaliação comparativa entre os governos FHC e Lula. Os resultados indicam que, inquestionavelmente, as principais variáveis macroeconômicas e sociais, bem como indicadores do estado das finanças públicas e da posição financeira externa do país, apresentaram comportamento mais virtuoso no governo Lula. Ressalta-se, entretanto, que especialmente no que se refere às políticas macroeconômicas, este não promoveu mudanças substantivas em relação ao que já estava sendo posto em prática ao final do governo FHC, de modo que grande parte da superioridade quanto aos resultados auferidos nesse campo não deve ser atribuída a uma superioridade de gestão, mas sim ao fato de a conjuntura econômica internacional ter sido, no conjunto, mais favorável ao Brasil no período 2003-2010 do que no período 1995-2002. Não obstante as diferenças significativas quanto aos números econômicos, o artigo apresenta algumas razões pelas quais se pode afirmar que ambos os governos deixaram muito a desejar em outros aspectos da realidade econômica e social brasileira, especialmente no que diz respeito a ausência de transformações estruturais e institucionais capazes de efetivamente colocar o Brasil na trilha já percorrida pelos países desenvolvidos.
\end{abstract}

Palavras-chave: Economia brasileira, política macroeconômica, setor público, finanças internacionais.

\section{Introdução}

Em janeiro de 2003, pela primeira vez na História do Brasil, um partido assumidamente de esquerda conseguiu eleger um ex-operário à Presidência da República. Findo o pleito eleitoral, enquanto as pessoas mais carentes aguardavam a posse do novo presidente com esperanças

1 Recebido em: 20/09/2010; Aceito em: 15/12/2010.

2 Doutor em Economia pela USP e Professor Associado do Departamento de Economia Rural da UFV.

E-mail: jmasilva@ufv.br

3 Doutor em Economia Aplicada pela UFV e Professor Adjunto da UFSM. E-mail: daniel.coronel@ufv.br 
renovadas, as mais ricas viveram dias de suspense. Contudo, coerente com o que havia declarado na publicação da Carta ao Povo Brasileiro, em junho de 2002, o presidente Luiz Inácio Lula da Silva estabeleceu o compromisso de manter a estabilidade macroeconômica sob os fundamentos alicerçados nos dois mandatos anteriores de Fernando Henrique Cardoso (FHC). Apesar de não ter acontecido muitas transformações progressistas ${ }^{4}$, de ter surgido protestos da esquerda e dissidências partidárias, foi possível reestabelecer a tranquilidade no meio empresarial.

Por outro lado, em conformidade com as promessas de campanha, o Governo deu início a uma política distributiva voltada para a redução da pobreza. Até o final do segundo mandato, foi empreendida, mediante elevação real do salário mínimo, a ampliação do acesso a aposentadorias de não contribuintes do INSS e lançamento de programas de apelo popular, como os denominados Fome Zero, Bolsa Família, Luz para Todos ${ }^{5}$.

Programas desse tipo já haviam sido lançados no governo FHC, como o Bolsa Escola, mas de uma forma menos ousada, haja vista sua incoerência com os fundamentos neoliberais da política econômica. Livre de tais restrições, o PT fez o mesmo que o PSDB no uso de programas populistas, bem como na distribuição de recursos públicos para fazer publicidade das ações do Governo e construir as alianças necessárias ao alcance de maioria nas votações do Congresso Nacional.

No início do seu primeiro mandato, com a nomeação de Henrique Meirelles para a presidência do Banco Central, foi possível perceber a intenção de dar continuidade à política monetária do governo $\mathrm{FHC}$, com seus objetivos essenciais e as implicações fiscais e orçamentárias, que exigiam a continuidade da DRU e outros dispositivos de sustentação do Plano Real. Assim, diferentemente do que acabou acontecendo no campo político, em decorrência de alguns escândalos como o "mensalão", que

Boas exposições de motivos de decepções podem ser encontradas em Paulani (2004).

As lideranças do PT também souberam fazer bom uso do carisma do presidente e sua identificação antropológica com o povo brasileiro. Em conjunto, todos esses fatores explicam bem a conquista de três mandatos consecutivos, revelando a execução de um projeto de poder até aqui muito bem sucedido. 
culminou na deposição do Ministro chefe da Casa Civil, o primeiro mandato do governo Lula transcorreu sem maiores sobressaltos no campo econômico. Porém, a contragosto dos que preferiam uma política de estabilização menos ortodoxa e ansiavam por um projeto nacionaldesenvolvimentista de certa envergadura ${ }^{6}$.

No segundo mandato, iniciado em janeiro de 2007, deu-se continuidade à política monetária herdada do governo FHC, como demonstra os limites estipulados para as metas de inflação estabelecidas pelo Comitê de Política Monetária do Branco Central (COPOM) e a vigência de juros ainda elevados para um país que, praticamente, havia consolidado sua estabilidade monetária. A diferença mais notável em relação ao primeiro mandato foi a intensificação da política distributiva e o maior grau de liberdade para o crescimento econômico, sendo suficiente para que alguns economistas alinhados com o governo chamassem esse período do governo Lula de "novo desenvolvimentismo".

Tomando como referência um trabalho anterior de Alves da Silva (2003), este artigo tem por objetivos identificar o comportamento das principais variáveis macroeconômicas durante o governo Lula, em termos comparativos com o ocorrido no governo de FHC, e fornecer explicações para as diferenças de resultados entre ambos além de constituir mais uma referência para estudos sobre a economia brasileira.

Fora essa introdução, o trabalho desenvolve-se em três seções e uma conclusão. Na segunda seção discute-se o comportamento das grandes variáveis objetivo da política de estabilização e alguns indicadores sócioeconômicos. Na terceira e quarta são examinadas as principais implicações nas finanças públicas e situação financeira externa do país.

\footnotetext{
Em vez disso, o que se viu foi o lançamento do Plano de Aceleração do Crescimento, popularizado pela sigla PAC, de natureza semelhante aos denominados Brasil em Ação e Avança Brasil, do governo FHC, programas desarticulados e que, face as carências de natureza estrutural e institucional do Brasil, podem ser considerados como de muito de baixo alcance.

Veja-se Mercadante (2010).
} 


\section{Comportamento das grandes variáveis macroeconômicas e indicadores socioeconômicos}

No que concerne ao comportamento da taxa de inflação, a Tabela 1 mostra que, durante o período de vigência do sistema de metas iniciado em 1999, com a posse de Armínio Fraga na presidência do Banco Central, a política monetária nos oito anos do governo Lula aparenta ter sido mais eficiente do que a dos quatro anos anteriores do governo FHC, caso se considere, como medida dessa eficiência, o desvio das taxas de inflação efetivamente registradas em relação às metas previamente estabelecidas. Conforme indicado nas duas últimas colunas da Tabela 1, tanto a taxa média de inflação anual apurada pelo IBGE quanto o desvio médio em relação ao centro da meta foram significativamente mais baixos no período correspondente ao governo Lula do que no de seu antecessor. No último ano do governo FHC houve um repique inflacionário que forçou a uma revisão para cima da meta de inflação no primeiro ano do governo Lula, fato que os militantes do PT justificaram como "herança maldita".

Tabela 1. Metas e taxas de inflação, 1999 - 2010

\begin{tabular}{cccc}
\hline Período & $\begin{array}{c}\text { Meta } \\
(1)\end{array}$ & $\begin{array}{c}\text { Inflação } \\
(2)\end{array}$ & $\begin{array}{c}\text { Desvio } \\
(2-1)\end{array}$ \\
\hline 1999 & 8.00 & 8.94 & 0.94 \\
2000 & 6.00 & 5.97 & -0.03 \\
2001 & 4.00 & 7.67 & 3.67 \\
2002 & 3.50 & 12.53 & 9.03 \\
\hline Média & 5.37 & 8.78 & 3.40 \\
\hline 2003 & 8.50 & 9.30 & 0.80 \\
2004 & 5.50 & 7.60 & 2.10 \\
2005 & 4.50 & 5.69 & 1.19 \\
2006 & 4.50 & 3.14 & -1.36 \\
2007 & 4.50 & 4.46 & -0.04 \\
2008 & 4.50 & 5.90 & 1.40 \\
2009 & 4.50 & 4.31 & -0.19 \\
2010 & 4.50 & 5.91 & 1.41 \\
\hline & & & \\
\hline Média & 5.13 & 5.79 & 0.66 \\
\hline
\end{tabular}

Fonte: Organizado pelos autores a partir de dados do Instituto de Pesquisa Econômica Aplicada (IPEA, 2011) e Instituto Brasileiro de Geografia e Estatística (IBGE, 2011). 
Se as autoridades monetárias forem culpadas por um desvio em relação ao centro da meta que ultrapassa o limite máximo aceitável, isso pode ocorrer por falta de credibilidade na política ou por irrealismo na definição da meta. Conforme mostrado na Tabela 1, durante os quatro anos de vigência do sistema de metas no governo FHC, o centro da meta foi sucessivamente reduzido, caindo de 8\% em 1999 para 3,5\% em 2002. No biênio 1999/2000, a taxa de inflação efetiva esteve muito próxima do centro da meta, mas no seguinte houve dois estouros sucessivos. Há fortes razões para crer que estes aconteceram em função da definição de metas ambiciosamente baixas, ou pelo menos não devidamente precedidas de uma cuidadosa análise das tendências de curto prazo da economia mundial ${ }^{8}$. Assim, os resultados melhores da política monetária no governo Lula tanto podem ser devidos a uma condução mais realista da política monetária quanto a uma conjuntura inflacionária mundial mais favorável.

A Tabela 2 mostra que quanto às condições de crescimento econômico e emprego, as diferenças entre os dois governos não são muito significativas. Embora a taxa média de crescimento do PIB seja cerca de $60 \%$ mais alta no governo Lula esta deve ser considerada insatisfatória para um país com o potencial do Brasil. $\mathrm{O}$ mesmo pode ser dito quanto à taxa de investimento que, desde o início do governo $\mathrm{FHC}$ até o final do governo Lula, manteve-se muito aquém do desejável, segundo padrões internacionais.

A análise dos indicadores socioeconômicos, representados na Tabela 3, indica que, para o conjunto da classe trabalhadora e para a população mais carente, o governo Lula foi bem mais favorável, o que explica os sucessos eleitorais do PT. A taxa média de crescimento do salário mínimo real foi significativamente mais elevada que a do período FHC e as políticas sociais assistencialistas ou protecionistas parecem ter contribuído para a redução dos níveis de pobreza e indigência. Em consequência,

Conforme evidenciado empiricamente no estudo de Borio e Filarto (2003), quanto maior a globalização econômica, menor o poder das políticas monetárias internas nos países de economia aberta. Isso parece não ter sido devidamente levado em consideração pelas autoridades monetárias brasileiras da época. 
essas políticas tiveram certo efeito redistributivo, conforme indica o comportamento do índice de Gini, que apresentou uma queda de quase quatro pontos percentuais entre o início do governo FHC e o final do governo Lula. Há que se considerar, no entanto, que seria estranho se isso não acontecesse durante o governo de um partido que leva o nome de Partido dos Trabalhadores.

Tabela 2. Crescimento, emprego e investimento, 1995 - 2010

\begin{tabular}{cccrrc}
\hline Período & \multicolumn{2}{c}{$\begin{array}{c}\text { Variação real } \\
\text { do PIB (\%) }\end{array}$} & \multicolumn{2}{c}{ Taxas de desemprego (\%) } & Taxa de \\
& IBGE & SEADE* & SEADE** & investimento \\
\hline 1995 & 4.2 & 6.7 & 9.0 & 13.2 & 18.32 \\
1996 & 2.2 & 7.6 & 9.9 & 15.0 & 16.87 \\
1997 & 3.4 & 8.5 & 10.2 & 15.7 & 17.37 \\
1998 & 0.0 & 9.7 & 11.7 & 18.2 & 16.97 \\
1999 & 0.3 & 10.4 & 12.1 & 19.3 & 15.66 \\
2000 & 4.3 & ND & 11.0 & 17.7 & 16.80 \\
2001 & 1.3 & 10.0 & 11.2 & 17.6 & 17.03 \\
2002 & 2.7 & 9.9 & 12.1 & 19.0 & 16.39 \\
\hline Média & 2.2 & 8.9 & 10.9 & 16.9 & 16.93 \\
\hline 2003 & 1.1 & 10.5 & 12.7 & 19.9 & 15.28 \\
2004 & 5.7 & 9.7 & 11.8 & 18.8 & 16.10 \\
2005 & 3.2 & 10.2 & 10.6 & 17.0 & 15.94 \\
2006 & 4.0 & 9.2 & 10.4 & 15.9 & 16.43 \\
2007 & 6.1 & 8.9 & 10.1 & 15.0 & 17.44 \\
2008 & 5.1 & 7.8 & 8.8 & 13.0 & 19.11 \\
2009 & -0.2 & 9.1 & 9.4 & 12.8 & 16.91 \\
2010 & - & - & 9.1 & 12.4 & - \\
\hline Média & 3.6 & 9.3 & 10.4 & 15.6 & 16.74 \\
\hline
\end{tabular}

* desemprego aberto na região metropolitana de São Paulo; ** inclui desemprego oculto por desalento e trabalho precário.

Fontes: Organizado pelos autores a partir de dados do Banco Central do Brasil (2011), do Instituto de Pesquisa Econômica Aplicada (IPEA, 2011) e do Departamento Intersindical de Estatística e Estudos Socioeconômicos DIEESE (2010).

Outra diferença marcante entre os dois governos diz respeito ao comportamento do consumo das famílias. Conforme indicado na Tabela abaixo, no governo Lula a taxa média de crescimento dessa variável foi cerca de $75 \%$ mais alta que a do governo FHC. As políticas sociais contribuíram significativamente para esse resultado, além das condições de crédito que se tornaram mais favoráveis. Embora no Brasil o custo do 
crédito continue sendo um dos mais altos do mundo, a ampliação dos prazos de financiamento e outros mecanismos, como por exemplo, o crédito consignado, teve impacto considerável nas aquisições de bens de consumo durável. Aliado ao crescimento das exportações e menor aperto dos gastos públicos verificado no governo Lula, o comportamento da variável consumo das famílias constituiu um importante fator de sustentação do nível da atividade econômica. Para isso também contribuiu a política fiscal de redução de IPI sobre automóveis ${ }^{9}$ e bens duráveis, em resposta aos reflexos da crise econômica mundial de 2007. Assim, quanto ao comportamento das grandes categorias da demanda agregada, o que ambos os governos tiveram em comum foi a vigência de baixas taxas de investimento público e privado.

Tabela 3. Indicadores socioeconômicos, 1995 - 2009

\begin{tabular}{cccccc}
\hline Período & $\begin{array}{c}\text { Salário } \\
\text { mínimo real } \\
(\Delta \%)\end{array}$ & $\begin{array}{c}\text { Consumo das } \\
\text { famílias } \\
(\Delta \%)\end{array}$ & $\begin{array}{c}\text { Taxas de Pobreza e } \\
\text { indigência }\end{array}$ & $\begin{array}{c}\text { Índice de } \\
\text { Gini }\end{array}$ \\
\hline 1995 & -0.1 & 8.62 & 35.08 & 15.19 & 0.600507 \\
1996 & 4.3 & 3.24 & 34.73 & 15.63 & 0.602054 \\
1997 & 2.5 & 3.03 & 35.18 & 15.58 & 0.602092 \\
1998 & 4.0 & -0.72 & 33.97 & 14.52 & 0.600155 \\
1999 & 0.9 & 0.38 & 35.26 & 15.03 & 0.593974 \\
2000 & 3.4 & 4.03 & $\mathrm{ND}$ & $\mathrm{ND}$ & $\mathrm{ND}$ \\
2001 & 9.1 & 0.68 & 35.17 & 15.28 & 0.596082 \\
2002 & 2.6 & 1.93 & 34.40 & 13.99 & 0.589267 \\
\hline Média & 3.4 & 2.65 & 34.83 & 15.03 & 0.577330 \\
\hline 2003 & 0.7 & -0.78 & 35.79 & 15.20 & 0.583034 \\
2004 & 3.7 & 3.82 & 33.70 & 13.20 & 0.572372 \\
2005 & 7.0 & 4.47 & 30.82 & 11.49 & 0.569438 \\
2006 & 14.1 & 5.20 & 26.75 & 9.44 & 0.562936 \\
2007 & 6.0 & 6.07 & 24.24 & 8.65 & 0.556043 \\
2008 & 3.1 & 5.67 & 22.59 & 7.57 & 0.547563 \\
2009 & 7.2 & 4.19 & 21.42 & 7.28 & 0.542751 \\
\hline Média & 6.0 & 4.10 & 27.90 & 10.40 & 0.562019 \\
\hline
\end{tabular}

Fonte: Organizado pelos autores a partir de dados do Instituto de Pesquisa Econômica Aplicada (IPEA, 2011).

\footnotetext{
9 Para maiores detalhes sobre a redução de alíquotas e tributos propostos pelo governo Lula ver Coronel (2009).

10 A taxa de pobreza refere-se ao percentual de pessoas com renda domiciliar per capita inferior à linha de pobreza e a taxa de indigência ao percentual de pessoas com renda domiciliar per capita abaixo da linha de indigência. A linha de indigência, ou de extrema pobreza, é definida pela estimativa do valor de uma cesta alimentar com o mínimo de calorias necessárias à subsistência de uma pessoa. A linha de pobreza simplesmente definida como o dobro da linha de indigência.
} 


\section{A situação das Finanças Públicas}

O bem-estar econômico familiar depende das possibilidades de consumo dos bens privados e públicos. Como mostrado na seção anterior, a aquisição dos bens privados foi maior no governo Lula. Entretanto, quanto aos públicos as diferenças não são significativas. No governo FHC, as medidas de sustentação do Plano Real, entre elas o contingenciamento de verbas públicas, mediante dispositivo da Desvinculação de Receitas da União (DRU) e outros mecanismos, como a Lei de Responsabilidade Fiscal, implicaram em uma redução dos gastos com a provisão de públicos fundamentais. Assim, além do aumento do desemprego e redução do crescimento do PIB, decorrentes do Plano Real, deve ser imputada ao governo FHC a responsabilidade por outros sacrifícios sociais decorrentes de restrições impostas ao consumo dos bens públicos ${ }^{11}$. Uma vez que o governo Lula, no intuito de evitar qualquer risco à estabilidade monetária herdada, manteve quase intactos os dispositivos de contenção fiscal, pode-se dizer que ele contribuiu para o aumento do contraste brasileiro entre a opulência privada e a miséria pública. O consumo de bens tecnológicos (telefones celulares, máquinas fotográficas digitais, automóveis, computadores pessoais, softwares) aumentou, mas as ofertas efetivas de produtos como leitos e equipamentos hospitalares, saneamento básico, tratamento de esgotos, habitação e urbanismo continuaram bem abaixo das demandas potenciais. Nisso e em condições extremamente atradas de prestação de serviços nas áreas de educação, justiça, segurança, saúde pública e proteção ambiental reside a grande distância entre o Brasil e os países desenvolvidos ${ }^{12}$.

Grande parte da escassez e precariedade da oferta de bens públicos essenciais pode ser atribuída à multibilionária conta de juros instaurada pela política monetária. Conforme indicado na Tabela 4, essa conta

\footnotetext{
11 São claras evidências disso a precarização de infra-estrutura de transporte e logística, a redução de verbas para educação superior, segurança pública e o déficit de investimentos em geração e distribuição de energia que culminaram no "apagão", entre outros fatos da história econômica brasileira durante o governo FHC, por força dos quais se pode dizer que o êxito do Plano Real no combate à inflação brasileira, como já tivemos a oportunidade de mencionar em outras ocasiões, pode ser considerado como uma típica "Vitória de Pirro".

12 Assim, enquanto as taxas de inflação diminuíam, outras taxas de crescimento de indicadores sociais, como índices de morte violenta por acidentes e crimes, e outros índices de qualidade de vida "ou qualidade de morte" pioravam sistematicamente.
} 
apresentou um crescimento vertiginoso entre o segundo mandato de FHC e o primeiro mandato de Lula. Além da compressão de outras formas de gasto público, necessária para lhe dar cobertura, a conta juros também contribuiu significativamente, ainda que de forma indireta, para o aumento da carga tributária, uma vez que a geração de superávits fiscais necessários para manter a taxa de endividamento público, dentro de limites aceitáveis, impõe que outros projetos de governo sejam viabilizados por aumentos de receita tributária. Nesse aspecto, reside outro ponto em comum dos dois governos: ambos se mostraram muito eficazes em ampliar a arrecadação, valendo-se dos mais sutis estratagemas.

Tabela 4. Indicadores de tributação e contas públicas, 1995 - 2009

\begin{tabular}{ccccc}
\hline Período & $\begin{array}{c}\text { Carga tributária } \\
\text { (média do período) }\end{array}$ & \multicolumn{2}{c}{ Conta de juros } & SFP (R\$ bilhões) \\
\hline $1995-1998$ & 26.74 & 211.4 & & -6.5 \\
$1999-2002$ & 30.74 & 365.8 & 73.0 & 165.4 \\
$2003-2006$ & 33.67 & 589.8 & 61.2 & 291.9 \\
$2007-2009$ & 34.96 & 494.1 & -16.1 & 260.7 \\
$1995-2009$ & 31.52 & 1661.1 & & 711.5 \\
\hline
\end{tabular}

Fonte: Organizado pelos autores a partir de dados do Banco Central do Brasil (2011).

Como mostrado na Tabela 4, a carga tributária tem aumentado sistematicamente durante os mandatos dos presidentes Lula e FHC. Depois do Plano Real, o povo brasileiro passou a conviver com taxas de inflação mais civilizadas, porém com uma carga tributária tão pesada quanto paradoxal diante da carência de bens públicos. Mesmo quando a taxa de inflação caiu bem abaixo do centro da meta, como em 2006, as autoridades monetárias conservaram uma soberania suficiente para resistir às pressões dos empresários em prol de reduções mais incisivas nas taxas de juros. Iniciou-se um processo de redução da taxa básica, porém de forma muito gradual. Além disso, grande parte folga nas contas públicas, advinda da redução da conta juros e da elevação da receita, foi consumida em gastos de custeio com ampliação da máquina estatal. ${ }^{13}$ Apesar disso,

\footnotetext{
${ }_{13}$ De fato, no aparelhamento partidário do governo Lula acabou se revelando bem mais arrojado que os antecessores no aparelhamento partidário do Estado, mediante ampliação do número de ministérios, cargos e funções comissionadas. Assim, a folga orçamentária decorrente da redução da taxa de juros que poderia ser usada para ampliar a oferta de bens públicos parece ter servido mais para ampliar o inchaço burocrático estatal.
} 
a conjugação de juros mais baixos e o crescimento do PIB e das exportações permitiram uma notável reversão das taxas de endividamento interno e externo em relação aos níveis que determinaram a crise cambial no segundo mandato de FHC. Conforme indicado na Tabela 5, a dívida líquida do setor público, que havia ultrapassado a marca dos $50 \%$ do PIB na transição dos governos, passa a apresentar uma tendência declinante, especialmente no segundo mandato do presidente Lula. Para os militantes do PT, o fato da taxa média de endividamento público ter superado a marca registrada no governo FHC foi justificado como outra "herança maldita”.

Em face da reversão das contas externas, que no governo FHC deu início a uma fase de excepcional crescimento das exportações, a acumulação de reservas cambiais foi tão expressiva que de devedor externo, no governo FHC, o setor público brasileiro passou a credor no governo Lula, conforme indicam as quatro últimas linhas da Tabela 5.

Favorecido por uma conjuntura internacional mais propícia, o governo Lula foi marcado por uma sensível melhora no estado das finanças públicas e das contas externas, mas no conjunto foi decepcionante aos que esperavam transformações estruturais e institucionais mais progressistas. Em termos de ações de cunho estrutural, criou um novo modelo para o setor elétrico, forçado pelas pressões das circunstâncias do "apagão", bem como outras ações emergenciais que serviram para interromper o sucateamento das rodovias e instalações públicas federais. Como iniciativas mais notáveis restam alguns projetos de grande porte como o caso da transposição do Rio São Francisco, da Hidrelétrica de Belo Monte e da implantação do trem bala ligando as duas maiores regiões metropolitanas do Brasil ${ }^{14}$.

\footnotetext{
${ }^{14}$ Segundo os críticos, a transposição do Rio São Francisco é mais uma obra tipicamente ad hoc, como foram tantas outras obras hídricas para o Nordeste, feitas no passado, que serviram mais para beneficiar empresários e "caciques regionais" do que promover o desenvolvimento sócio-econômico da região, razão pela qual o povo do semi-árido, continua dependente de toda sorte de ajudas governamentais, como inválidos que precisam da esmola. O projeto do trem-bala também é outro grande exemplo de obra desarticulada, cuja viabilidade não pode ser aferida em termos de uma ordem de prioridades pré-estabelecida. Se for para retomar investimentos na reconstrução da malha ferroviária brasileira será que é preferível começar pela implantação de um trem de alta velocidade para transporte de passageiros de alta renda? Respostas a essas e outra questões requerem a elaboração de um plano integrado de transportes para o Brasil, que ainda está para ser feito.
} 
Tabela 5. Dívida líquida do setor público, 1995 - 2009

\begin{tabular}{ccccccc}
\hline & \multicolumn{2}{c}{ Total } & \multicolumn{2}{c}{ Interna } & \multicolumn{2}{c}{ Externa } \\
\hline Período & R\$ Milhöes & \% do PIB & RS Milhóes & \% do PIB & RS Milhöes & \% do PIB \\
\hline 1995 & 208.460 .3 & 28.0 & 162.376 .2 & 24.4 & 38.132 .4 & 5.1 \\
1996 & 269.193 .4 & 30.7 & 237.600 .3 & 27.1 & 31.593 .2 & 3.6 \\
1997 & 308.426 .3 & 31.8 & 269.846 .0 & 27.9 & 38.580 .3 & 4.0 \\
1998 & 385.869 .6 & 38.9 & 328.693 .0 & 33.2 & 57.176 .6 & 5.8 \\
1999 & 516.578 .7 & 44.5 & 407.809 .9 & 35.2 & 108.768 .8 & 9.4 \\
2000 & 563.163 .1 & 45.5 & 451.840 .9 & 36.5 & 111.322 .3 & 9.0 \\
2001 & 680.077 .7 & 49.9 & 551.349 .1 & 40.4 & 128.728 .6 & 9.4 \\
2002 & 896.096 .3 & 51.3 & 658.556 .8 & 37.7 & 237.593 .4 & 13.6 \\
\hline Média & 478.483 .18 & 40.08 & 383.509 .03 & 32.80 & 93.986 .95 & 7.49 \\
\hline 2003 & 933.630 .1 & 53.5 & 739.024 .1 & 42.4 & 194.606 .0 & 11.2 \\
2004 & 981.972 .9 & 48.2 & 824.991 .2 & 40.5 & 156.981 .7 & 7.7 \\
2005 & 1.035 .278 .4 & 48.0 & 964.657 .8 & 44.7 & 70.620 .5 & 3.3 \\
2006 & 1.112 .701 .3 & 45.9 & 1.138 .232 .3 & 46.9 & -25.531 .0 & -1.1 \\
2007 & 1.200 .799 .1 & 43.9 & 1.397 .393 .6 & 51.1 & -196.594 .5 & -7.2 \\
2008 & 1.153 .631 .5 & 38.8 & 1.482 .193 .0 & 49.9 & -328.561 .5 & -11.1 \\
2009 & 1.345 .325 .0 & 42.9 & 1.614 .176 .7 & 52.3 & -287.930 .0 & -9.2 \\
\hline Média & 957.801 .50 & 45.89 & 842.891 .03 & 46.8 & -59.486 .97 & -0.91 \\
\hline
\end{tabular}

Fonte: Organizado pelos autores a partir de dados do Banco Central do Brasil (2011).

O governo Lula começou acenando com reformas institucionais importantes, como as sempre proclamadas reforma tributária e política. Mas nada foi adiante. A reforma política não passou da retórica, enquanto que um arremedo de reforma tributária chegou a ser colocado no papel, mas depois de muito embate entre grupos de interesse, ficou esquecida nas gavetas do Congresso Nacional. Assim, depois de oito mandatos presidenciais democráticos, o Brasil permanece com um sistema tributário complicado, razão pela qual a carga tributária, além de elevada, em termos comparativos com os países desenvolvidos, é extremamente onerosa para o setor produtivo e desigualmente distribuída entre as classes sociais.

Pelo fato de ser oneroso ao setor produtivo, a ponto de constituir o principal fator na formação do chamado custo Brasil, o atual sistema tributário nacional impõe obstáculos à geração de empregos formais, em detrimento da classe trabalhadora. Além disso, é excessivamente concentrado em tributos indiretos sobre bens e serviços, que incidem de forma mais pesada sobre os consumidores mais pobres. Tal incidência regressiva poderia ser compensada por uma escala de alíquotas progressivas sobre o Imposto 
de Renda. Mas, coerentemente com a estratégia de dar aos pobres sem incomodar os ricos, o IRPF continuou, como no governo FHC, um imposto de maior incidência sobre os assalariados da classe média.

Conforme estimativas do Instituto Brasileiro de Planejamento Tributário, menos de 5\% da arrecadação tributária total nos três níveis de governo provêm de impostos sobre o patrimônio, enquanto que cerca de $75 \%$ provêm de tributação sobre a produção, a comercialização de bens e serviços e os rendimentos do trabalho. ${ }^{15}$ Portanto, em uma avaliação geral, pode-se dizer que, assim como na política monetária, o governo Lula também revelou-se conservador quanto à política fiscal.

\section{A posição Externa}

No que tange à posição da economia brasileira no cenário econômico internacional, o governo Lula foi caracterizado por uma evolução das contas externas em contraste com o quadro de vulnerabilidade que a política neoliberal instaurou no governo FHC. A reversão das contas externas havia sido iniciada no segundo mandato deste Presidente com a desvalorização do Real e as medidas subsequentes que sepultaram a estratégia da âncora cambial estabelecida por Pedro Malan e Gustavo Franco.

Além disso, foi favorecido por uma conjuntura econômica internacional mais favorável do que a do governo FHC, sobre o qual repercutiram efeitos de crises econômicas mundiais (1997/98 e 2001) mais negativos dos que os impactos da recente crise de 2008 enfrentada pelo governo Lula. Conforme evidenciado na Tabela 6, favorecido por uma fase de crescimento do comércio mundial, em larga medida puxado pelo crescimento econômico da China e outros países emergentes, o primeiro mandato de Lula marcou uma fase de grande crescimento tanto das exportações quanto das importações. Embora as importações também

15 O principal imposto brasileiro de incidência patrimonial é o IPVA, que embora seja a segunda fonte de receita tributária dos Estados, depois do ICMS, responde por apenas cerca de 5\% da arrecadação estadual. 
tenham crescido a ponto de seu total acumulado ter mais do que duplicado nos oito anos do governo Lula, em relação aos do governo FHC, no período 2003-2010, o valor total acumulado das exportações foi cerca de $30 \%$ maior que o das importações. Isso foi suficiente para inverter a posição da balança comercial, que de um saldo negativo acumulado de U\$8,5 bilhões, no período 1995-2002, passou para um saldo positivo acumulado de U\$260,1 bilhões no período 2003-2010. Em conjunto com outros fatores, isso contribuiu para restaurar a confiança dos investidores externos. Em consequência, o Brasil passou a receber novo afluxo de capital estrangeiro tão intenso a ponto de fazer o nível das reservas internacionais superar o total da dívida externa registrada do país. $\mathrm{Na}$ campanha de Dilma Roussef, esse dado foi usado para dar a entender que na gestão Lula o Brasil havia passado de devedor a credor internacional. Essa, entretanto, é uma interpretação enganosa.

Tabela 6 - Balanço de pagamentos em transações correntes, em U\$ bilhões, 1995 - 2010

\begin{tabular}{ccccccc}
\hline Periodo & $\begin{array}{c}\text { Exportaçóes } \\
(1)\end{array}$ & $\begin{array}{c}\text { Importaçöes } \\
(2)\end{array}$ & $\begin{array}{c}\text { Saldo } \\
\text { Comercial } \\
(1)-(2)\end{array}$ & $\begin{array}{c}\text { Serviços e rendas } \\
\text { (Saldo liquido) }\end{array}$ & $\begin{array}{c}\text { Transaçöes } \\
\text { correntes }\end{array}$ & $\begin{array}{c}\text { Taxa de } \\
\text { cámbio }\end{array}$ \\
\hline 1995 & 46.5 & 50.0 & -3.5 & -18.5 & -18.4 & 0.97 \\
1996 & 47.7 & 53.3 & -5.6 & -20.3 & -23.5 & 1.04 \\
1997 & 53.0 & 59.7 & -6.8 & -25.5 & -30.4 & 1.11 \\
1998 & 51.1 & 57.7 & -6.6 & -28.3 & -33.4 & 1.21 \\
1999 & 48.0 & 49.2 & -1.2 & -25.8 & -25.3 & 1.84 \\
2000 & 55.1 & 55.8 & -0.7 & -25.0 & -25.2 & 1.96 \\
2001 & 58.2 & 55.6 & 2.6 & -27.5 & -23.2 & 2.36 \\
2002 & 60.4 & 47.2 & 13.2 & -23.1 & -7.6 & 3.63 \\
\hline $1995-2002$ & 420.0 & 428.5 & -8.5 & -194.0 & -187.0 & - \\
\hline 2003 & 73.1 & 48.3 & 24.8 & -23.5 & 4.2 & 2.93 \\
2004 & 96.5 & 62.8 & 33.7 & -25.2 & 11.7 & 2.72 \\
2005 & 118.3 & 73.6 & 44.7 & -34.3 & 14.0 & 2.29 \\
2006 & 137.8 & 91.4 & 46.4 & -37.1 & 13.6 & 2.15 \\
2007 & 160.6 & 120.6 & 40.0 & -42.5 & 1.5 & 1.79 \\
2008 & 197.9 & 173.1 & 24.8 & -57.3 & -28.2 & 2.39 \\
2009 & 153.0 & 127.6 & 25.4 & -52.9 & -24.3 & 1.75 \\
2010 & 201.9 & 181.6 & 20.3 & -70.6 & -47.6 & \\
\hline $2003-2010$ & 1139.1 & 879.0 & 260.1 & -343.5 & -55.1 & - \\
\hline
\end{tabular}

Fonte: Organizado pelos autores a partir de dados do Banco Central do Brasil (2011). 
A situação financeira de um país é determinada pela evolução conjunta da conta de transações correntes do balanço de pagamentos e a posição das reservas internacionais. Contabilmente, um déficit de transações correntes aumenta o passivo externo da nação e vice-versa. Como indicado na Tabela 6, o saldo acumulado de transações correntes foi negativo no governo Lula, embora tenha apresentado saldos positivos nos anos de 2003 a 2007. Portanto, o passivo externo também cresceu nesse governo. Entretanto, conforme indicado na Tabela 7, as entradas de capital estrangeiro, devido aos investimentos estrangeiros diretos e de portfólio, que, no conjunto, apresentaram volume muito superior ao déficit de transações correntes, implicou em acumulação de reservas suficientemente rápida para determinar, em pouco tempo, uma posição financeira internacional mais folgada, conforme demonstrado pelos números da Tabela 8.

Tabela 7 - Balanço de Pagamentos - conta de capital, em U\$ bilhões, $1995-2010$

\begin{tabular}{ccccc}
\hline Período & $\begin{array}{c}\text { Investimento estrangeiro líquido } \\
\text { Portfólio }\end{array}$ & $\begin{array}{c}\text { Resultado global } \\
\text { ID BP }\end{array}$ & $\begin{array}{c}\text { Reservas* } \\
\text { Internacionais }\end{array}$ \\
\hline 1995 & 24.8 & 3.3 & 12.9 & 51.8 \\
1996 & 26.1 & 11.2 & 8.7 & 60.1 \\
1997 & 39.5 & 17.8 & -7.9 & 52.1 \\
1998 & 31.8 & 26.0 & -8.0 & 34.4 \\
1999 & 18.3 & 26.9 & -7.8 & 23.9 \\
2000 & 19.8 & 30.5 & -2.3 & 31.5 \\
2001 & 0.9 & 24.7 & 3.3 & 27.8 \\
2002 & -4.8 & 14.1 & 0.3 & 16.3 \\
\hline Média & 19.5 & 19.3 & -0.1 & 37.2 \\
\hline 2003 & 5.1 & 9.8 & 8.5 & 20.5 \\
2004 & -4.0 & 8.3 & 2.2 & 27.5 \\
2005 & 6.7 & 12.5 & 4.3 & 53.8 \\
2006 & 9.1 & -9.3 & 30.6 & 85.8 \\
2007 & 48.1 & 27.5 & 87.5 & 180.3 \\
2008 & -0.8 & 24.6 & 3.0 & 206.8 \\
2009 & 46.2 & 31.7 & 46.7 & 239.1 \\
2010 & 67.8 & 36.9 & 49.1 & - \\
\hline Média & 22.3 & 17.8 & 28.9 & 116.3 \\
\hline
\end{tabular}

* No conceito de liquidez internacional

Fonte: Organizado pelos autores a partir de dados do Banco Central do Brasil (2011). 
Depois do ataque especulativo contra o Real, que deixou o país no limiar da insolvabilidade, na fase de transição do governo FHC para o governo Lula, a partir de 2003 as reservas voltaram a crescer. Inicialmente, esse crescimento foi impulsionado principalmente pela reversão do balanço de pagamentos em transações correntes, que de deficitário em todo o período FHC, passou a ser superavitário no governo Lula, permanecendo assim por cinco anos seguidos, graças a um excepcional desempenho da balança comercial. Os índices de risco-Brasil iniciaram uma trajetória fortemente declinante a partir de $2003^{16}$. A partir daí, o Brasil voltou progressivamente a tornar-se cada vez mais atraente para os investidores internacionais, a ponto de no segundo governo Lula passar a apresentar uma captação de capital estrangeiro maior do que o primeiro governo de FHC. Verifica-se, assim, no segundo mandato de Lula, uma situação muito parecida com a presenciada nos primeiros anos do governo FHC em que um processo de valorização do Real em relação ao dólar se combinava com acumulação de reservas insuflada por afluxo de capital estrangeiro. Naquela época, isso contribuiu para criar um clima extremamente eufórico, que, entretanto, revelou ser apenas uma fase ascendente de um ciclo que trazia os elementos determinantes de sua própria reversão.

A partir de 2008, o balanço de pagamentos voltou a apresentar elevados déficits de transações correntes. Isso pode ser ou não o prenúncio de uma reversão do fluxo financeiro internacional enfrentado pelo Brasil, dependendo do comportamento das exportações nos anos seguintes uma vez que o estado de espírito dos investidores internacionais depende muito da relação dívida/exportações, que apresentou tendência declinante durante o governo Lula. Um motivo de preocupação quanto ao comportamento futuro das exportações está relacionado com o fato de seu crescimento durante o governo Lula ter sido acompanhado de aumento da importância de produtos básicos e semi-manufaturados na composição do valor exportado, uma vez que isso aumenta o potencial de instabilidade

\footnotetext{
${ }^{16}$ Embora como sugerem alguns estudos, como o de Almeida (2006), esse comportamento favorável dos indicadores de risco-Brasil se deveram mais ao clima de otimismo dos investidores internacionais do que a qualquer outro fator que possa ser considerado como mérito da economia brasileira.
} 
dessa variável. A participação desses produtos no valor total das exportações passou de cerca de $42 \%$ em 2005 para cerca de 54\% em 2009 , uma mudança muito significativa em prazo curto ${ }^{17}$.

Por outro lado, alguns números apresentados na Tabela 7 constituem outro motivo de preocupação quanto ao futuro da economia brasileira. Este diz respeito à crescente importância da entrada de capital estrangeiro na forma investimento de portfólio em relação a outras formas, tendência decorrente do processo de globalização financeira desencadeado na economia mundial, a partir da década 1980. Os números da primeira coluna da Tabela 7 dão bem a idéia do grau de volatilidade desse tipo de capital, cujo fluxo de entrada no período 2007/2009 variou quase cinqüenta bilhões de dólares de um ano para outro.

Tabela 8. Posição financeira externa, 1995 - 2009 (\%)

\begin{tabular}{|c|c|c|c|c|c|c|}
\hline Período & $\begin{array}{l}\text { Serviço da } \\
\text { dívida/exp. }\end{array}$ & $\begin{array}{c}\text { Dívida } \\
\text { total } / \mathrm{PIB}\end{array}$ & $\begin{array}{l}\text { Dívida total } \\
\text { líquida/PIB }\end{array}$ & $\begin{array}{c}\text { Reservas/ } \\
\text { divida }\end{array}$ & $\begin{array}{l}\text { Dívida } \\
\text { total/exp }\end{array}$ & $\begin{array}{c}\text { Dívida } \\
\text { líquida/exp. }\end{array}$ \\
\hline 1995 & 44.5 & 21.7 & 12.2 & 33.9 & 3.3 & 1.9 \\
\hline 1996 & 54.7 & 22.3 & 12.1 & 34.7 & 3.6 & 2.0 \\
\hline 1997 & 72.6 & 23.7 & 15.2 & 27.2 & 3.6 & 2.3 \\
\hline 1998 & 87.4 & 28.4 & 20.9 & 19.9 & 4.4 & 3.2 \\
\hline 1999 & 126.5 & 42.0 & 32.5 & 16.1 & 4.7 & 3.6 \\
\hline 2000 & 88.6 & 36.0 & 28.4 & 15.2 & 3.9 & 3.1 \\
\hline 2001 & 84.9 & 41.2 & 31.9 & 17.1 & 3.6 & 2.8 \\
\hline 2002 & 82.7 & 45.9 & 35.9 & 18.0 & 3.5 & 2.7 \\
\hline Média & 80.2 & 32.7 & 23.6 & 22.8 & 3.8 & 2.7 \\
\hline 2003 & 72.5 & 42.4 & 29.8 & 22.9 & 2.9 & 2.1 \\
\hline 2004 & 53.8 & 33.3 & 22.5 & 26.3 & 2.1 & 1.4 \\
\hline 2005 & 56.0 & 21.3 & 12.8 & 31.9 & 1.4 & 0.8 \\
\hline 2006 & 41.3 & 15.9 & 6.9 & 49.7 & 1.3 & 0.5 \\
\hline 2007 & 32.4 & 14.1 & -0.9 & 93.3 & 1.2 & -0.1 \\
\hline 2008 & 19.0 & 12.1 & -1.7 & 104.3 & 1.0 & -0.1 \\
\hline 2009 & 28.6 & 12.6 & -3.9 & 120.6 & 1.3 & -0.1 \\
\hline Média & 43.4 & 21.7 & 9.4 & 64.1 & 1.6 & 0.6 \\
\hline
\end{tabular}

Fonte: Organizado pelos autores a partir de dados do Banco Central do Brasil (2011)

\footnotetext{
17 O Brasil parece assim estar retrocedendo na história. Exporta café em grão e importa café solúvel de alta qualidade; exporta minério de ferro e importa produtos siderúrgicos, exporta celulose e importa papel, e assim por diante, numa tendência que tem sido chamada de reprimarização econômica.
} 


\section{Conclusão}

As passagens de Fernando Henrique Cardoso e Luiz Inácio Lula da Silva pela presidência da República Federativa do Brasil apresentam alguns pontos em comum. Ambos ficaram oito anos no poder e souberam fazer alianças capazes de assegurar apoio parlamentar majoritário nas duas casas do Congresso Nacional. Os mandatos de ambos foram também marcados por práticas de governo surpreendentes em relação ao que se poderia esperar dos partidos pelos quais foram eleitos. FHC, do Partido da Social Democracia Brasileira (PSDB) aderiu à doutrina neoliberal encampada pelos adversários da social democracia, enquanto que Lula, eleito por um partido assumidamente de esquerda, exerceu dois mandatos em clima de harmonia com os capitalistas e ricos proprietários ${ }^{18}$.

Essas semelhanças se refletiram na condução da política macroeconômica. O governo Lula deu continuidade a uma política monetária voltada prioritariamente para o objetivo de manter a estabilidade do Real (sem grandes alterações nos seus fatores sustentação, como a DRU e outros expedientes de elevação da carga tributária) seja por meio de criação de tributos adicionais, como a CPMF e a CIDE, maior rigor na fiscalização e mudanças de legislação visando aumentar a base de arrecadação dos impostos antigos. Em decorrência disso, se na era FHC o Brasil converteu-se em um "paraíso do rentier" e no "inferno fiscal" do setor produtivo, no governo Lula nada se fez de substantivo para alterar esse quadro.

Quanto ao alcance de objetivos propostos, uma análise dos indicadores de resultados mostra que a gestão de Lula foi mais bem sucedida. A taxa média de inflação no período 2002-2010 foi ligeiramente mais baixa do que a registrada no período 1995-2001, mas os desvios das taxas efetivas em relação às metas previamente estipuladas foram significativamente

\footnotetext{
${ }_{18}$ No que diz respeito à política externa, houve uma diferença marcante entre os dois governos. Enquanto o governo FHC deu motivos até para ser chamado de impatriótico, pela de pela postura subserviente aos interesses imperialistas investidos no Brasil, na era Lula, se não se pode dizer que o Itamarati tenha se notabilizado pela defesa intransigente do interesse nacional pelo menos foi bem mais "arisco" ao assédio das grandes potências.
} 
menores no segundo. Se bem que sem grandes alterações que pudessem sinalizar uma tendência definitivamente mais progressista para o Brasil, o comportamento dos indicadores do nível de atividade econômica e das condições de emprego e salário foi mais favorável no governo Lula. Combinado com um uso mais intensivo de políticas assistencialistas, isso foi suficiente para promover alterações no quadro distributivo favoráveis à parcela mais pobre e mais inculta do eleitorado, que contribuíram para levar o PT à vitória em três pleitos presidenciais sucessivos.

Quanto ao comportamento dos principais indicadores macrofinanceiros que costumam ser utilizados para avaliar sustentabilidade das contas públicas e das contas externas do país, não há dúvida que eles apresentaram evolução muito mais favorável no governo Lula, pelas razões descritas na terceira e na quarta seção desse artigo. Contudo, há que se ressalvar que para isso contribuiu muito o fato de a economia brasileira no período Lula ter sido "bafejada por ventos mais favoráveis soprando de fora para dentro".

Entretanto, as tendências de longo prazo da economia brasileira são pouco promissoras, por falta de um projeto de desenvolvimento de longo prazo contemplando transformações estruturais e institucionais necessárias para assegurar ao país melhorias significativas em indicadores de ambiente social, saúde, educação, ciência e tecnologia que de fato distinguem os países desenvolvidos dos subdesenvolvidos. Nesse aspecto, os dois governos foram omissos. O primeiro por acreditar ou fingir acreditar que o liberalismo econômico poderia fazer mais pelo desenvolvimento a longo prazo do que o ativismo estatal. O segundo porque tem lançado mão da uma espécie de estratégia política que consiste em "trabalhar em cima das carências mais urgentes do povo brasileiro". Por esses e outros motivos, que estão fora do escopo desse artigo, tanto FHC quanto Lula correm o risco de entrar para a história como governantes que tiveram mais em vista os projetos de poder de seus partidos do que planos de desenvolvimento para o Brasil. 


\section{Referências}

ALVES DA SILVA, J. M. Inventário macroeconômico do governo FHC. Revista de Economia e Agronegócios, v.1, n.3, p.283-314, 2003.

ALMEIDA, A. R. Globalização financeira, inserção externa e riscoBrasil. 2006. Tese (Doutorado em Economia Aplicada) - Universidade Federal de Viçosa, Viçosa, MG.

BANCO CENTRAL DO BRASIL- BC. Boletim. Disponível em: < http://www.bcb.gov.br/?BOLETIM>.Acesso em: 04 jan.2011.

BÓRIO, C. e FILARDO, A. Globalization and inflation: New cross evidence on the global determinants of domestic inflatio, Bank for international Settlements, março, 2006.

CORONEL, D.A. Impactos da política de desenvolvimento produtivo na economia brasileira. 2010. Tese (Doutorado em Economia Aplicada) - Universidade Federal de Viçosa, Viçosa, MG.

DEPARTAMENTO INTERSINDICAL DE ESTATÍSTICA E ESTUDOS SOCIOECONÔMICOS - DIEESE. Conjuntura. Disponível em: <http://www.dieese.org.br>. Acesso em 13 de jan. 2011.

INSTITUTO BRASILEIRO DE GEOGRAFIA E ESTATÍSTICA IBGE. Economia. Disponível em: 〈http://www.ibge.gov.br/home/ mapa site/mapa site.php\#economia >. Acesso em: 10 jan. 2011.

INSTITUTO BRASILEIRO DE PLANEJAMENTO TRIBUTÁRIO - IBPT. Carga Tributária. Disponível em: <http://www.ibpt.com.br/ home/publicacao.list.php?publicacaotipo_id=2>.Acesso em: 02 jan. 2011.

INSTITUTO DE PESQUISA ECONÔMICA APLICADA - IPEA. Macroeconômico. Disponível em: <http://www.ipeadata.gov.br/ ipeaweb.dll/ipeadata?591895718>.Acesso em: 03 jan. 2011. 
MERCADANTE, A. As bases do novo desenvolvimentismo no Brasil: análise do governo Lula (2003-2010). Tese (Doutorado em Economia) - Universidade Estadual de Campinas, Campinas, São Paulo, 2010.

MINISTÉRIO DA FAZENDA. Estatísticas. Disponível em: <http:// www.fazenda.gov.br>. Acesso em 15 de jan. 2011.

PAULANI, L. M. Quando o medo vence a esperança (um balanço da política econômica do primeiro ano do governo Lula). Crítica Marxista, v.19, n.1, p.11-26, 2004.

\begin{abstract}
Based on analysis of Brazilian economic indicators in the period 1995-2010, this paper aims to establish a comparative evaluation between FHC and Lula governments. The results indicate that the main macroeconomic and social variables as well as public finance indicators and external financial situation of the country showed a more virtuous behavior during Lula's government. It is noticed that, especially regarding to macroeconomic policies, Lula did not cause significant changes in relation to what was already being implemented at the end of FHC government. Therefore, most of the results should not be attributed to the superiority of management but to the fact that the international economic environment was more favorable to Brazil in the period of 2003-2010 than in 1995-2002. Considering the significant differences in the economic numbers, the paper presents some reasons why it is possible to say that both governments left much to be done in other aspects of Brazilian social and economic reality, mainly regarding the absence of a national strategic plan able to initiate a process of structural and institutional changes that can effectively put Brazil on a way already covered by developed countries.
\end{abstract}

Keywords: Brazilian economy, macroeconomic policy, public sector, international finances. 